\title{
Effect of Technology on Elementary Students' Reasoning \& Communication Skills in Science at Lebanese Private Schools: An Exploratory Study
}

\author{
Layal Omar Temsah, MA \\ Education Management, \\ Supervisor at Jamil Rawass Public Secondary School, Lebanon
}

Dalal Michel Moukarzel, PhD

Educational Sciences, Associate Professor

Saint-Joseph-University of Beirut, Lebanon

Doi:10.19044/esj.2018.v14n25p107 URL:http://dx.doi.org/10.19044/esj.2018.v14n25p107

\begin{abstract}
With the emergence of multiple technological tools for teaching science such as active boards, mobile devices and tabs, the effectiveness and appropriateness of these tools are yet questionable. Students' performance in science, especially in the Arab world, is still unsatisfactory as shown by the TIMMS results of 2007 and 2011. In Lebanon, it was interesting to understand what was being done, specifically in elementary schools, to improve students' outcomes prior to sitting for international exams. The purpose of this study was to explore the perceptions of Heads of private elementary schools, science coordinators, teachers, and students regarding the use of technology, and the extent to which these technologies were enhancing students' skills. Participants in this study were 164 grade- six students from three private schools in different regions of Beirut, the Lebanese capital. Participants also included three administrators and four teachers of whom three were also coordinators in the corresponding schools. Semi-structured interviews, class observations and questionnaires were used to triangulate the results. Findings revealed that the vision and mission of the school leadership, the teachers' practices associated with the appropriate integration of technology were key determinants for enhancing students' perceptions of improvement in reasoning and communication skills in science.
\end{abstract}

Keywords: Technology, science teaching, reasoning, communication

\section{Introduction}

With the outbreak of the technological revolution and the emergence of many trends and issues related to education and the twenty-first century 
skills, a need for addressing students' overall academic achievement and their cognitive development in response to advancements in science and technology is inevitable. Many recent studies have pointed out to the frequent use of technology among Asian societies though not as frequently for educational purposes (Efe, 2015; Sparapani \& Calahan, 2014). Modern science learning calls for the active-engagement of students in hands-on activities and inquiry processes in order to construct their knowledge and effectively communicate their understanding (Rappolt-Schlichtmann, Daley, Lim, Lapinski, Robinson, Johnson, 2013; Cakir, 2011; Kim,Van Tassel-Baska, Bracken, Feng, Stambaugh, 2014). Such active learning calls for enhanced critical thinking skills which are congruent with the $21^{\text {st }}$ century educational frameworks, tools, and instructional practices. The enhancement of these skills in science needs to cater for the subject-matter relevant barriers such as challenges in reading and writing and low motivation for learning science (Rappolt-Schlichtmann et al., 2013; Kim et al., 2014). Many recent studies have tackled these challenges and have emphasized the importance of the integration of technology in improving students' thinking skills and achievement (Becker \&Park, 2011; Cakir, 2011; Mashizi \& Rezaian, 2014; Hardy, Kloetzer, Moeller, and Sodian, 2010; Chang \& Kim, 2009). It also increased students' motivation to learn science and addressed the learning needs of the current "digital natives", defined by Chaves, Maia and Melo (2016), as subjects born in the modern generation with sophisticated cognitive abilities and different learning styles whereas "digital immigrants" were people born before the net revolution and currently using Information Communication Technologies (ICT) (p.349).

Other studies have shed light on the importance of mobile learning, collaborative modes of game-based learning, integrating E-books, using computer simulations, and the use of multimedia and its effects on science learning (Cakir, 2011; Liu, Scordio, Geurtz, Navarrette, Ko, and Lim, 2014; Hwang, Shi, and Chu, 2011; Wen, Chuang, and Kuo, 2012; Chen, Wang, and Lin, 2015). The extent to which the afore-mentioned technologies can improve the learning of science is still subject to research.

A study called TIMSS (Trends in International Mathematics and Science Study, 2011) was conducted by the International Association for the Evaluation of Educational Achievement (IEA) to measure students' achievement in Science and Mathematics. It showed that the cognitive domains that were assessed were knowledge, application, and reasoning. The study involved 300,000 grade-eight students from 42 countries in the world including 4000 students from Lebanon, with the collaboration of the National Center for Educational Research and Development (NCERD). Results revealed that Singapore was the first in Science achievement worldwide while Emirates was the first in Science among 42 participating Arab countries. Lebanon's rank was 39 in the world among 63 countries, and the tenth in the Arab countries 
(NCERD, 1999; OECD, 2009; OECD, 2013). According to this study, the percentage of students who used computers in learning science in Lebanon was only 14\%. TIMSS comparative study between 2007 and 2011 revealed a significant decline in students' performance in Lebanon among other Arab Countries. The main skills lacking included critical thinking, communication, and collaboration in addition to knowledge, application, information media and technology literacy. The investigation of critical thinking and communication skills for science learning through the lens of technology use was important for Al-Naqbi (2015) and Ayoub (2015).

In our study, we addressed two of the above-mentioned cognitive domains at the elementary school level, thus preceding grade eight, to investigate the reasons behind students' weaknesses. Our purpose was to explore the school Heads' and science teachers' perceptions of the effects of integrating technologies in science, and consequently to examine students' perceptions of using technology and its effects on their reasoning and communication skills. We focused specifically on finding answers to two main questions:

1- What are Head of schools' and science coordinators'/teachers' perceptions about the benefits of technology use in learning science in grade-six?

2- To what extent do technology means used in sixth-grade scienceclasses enhance students' perceptions of learning gains to improve their reasoning and communication skills?

We hypothesized that the use of technology in private schools in Beirut with students from grade six had a significant effect on their reasoning skills in science but a minor effect on their oral communication skills in science. We also hypothesized that it would not affect their written communication skills in science.

\section{Literature Review}

A study was conducted in Turkey about the self-efficacy levels of students from grades-six, seven, and eight. It was found that elementary school students' self-efficacy toward science and technology differed in terms of grade-level, parents' education and profession, and reading scientific books and documentaries with no difference for gender variables (Ucak \& Bag, 2012). Other studies found that teachers' self-efficacy in using technology affected the possibility for student-centered learning activities, which in turn required increasing the professional training of teachers to use technology (Coleman, Gibson, Cotton, Howell-Moroney \& Stringer, 2016; Efe, 2015).

Studies about the integration of technology involved the use of computers, multimedia, personal digital assistants and mobile learning (Coleman et al., 2016; Liu et al., 2014; Tay, Lim \& Lim, 2015; Sparapani \& 
Calahan, 2015). Other commonly used technologies included television, Internet, interactive white boards, equipment for science laboratories in addition to Web2.0 applications that encompassed the second-generation of Internet-based devices which provided users with opportunities to create, share, and add to existing content included in Blogs, Wikis, podcasting, instant messaging, video sharing, and social networks (Efe, 2015; Sparapani \& Calahan, 2015). Other prescribed technologies included E-books and science notebooks (Rappolt-Schlichtmann et.al, 2013; Wen, Chuang \& Kuo, 2012). The most recent educational technologies prescribed were Web 3.0 requiring technologies to be available at a low cost and used purposively from teacher to student, student to student, and student to teacher. Conditions for using information communication technologies included policy and school leadership, technological infrastructure, curriculum and assessment, teachers' beliefs and practices and professional development (Sparapani \& Calahan, 2014; Tay et.al, 2015). A study by Becker and Park (2011) emphasized the positive effect of integrative approaches among Science, technology, Engineering, and Mathematics (STEM) and proved that the largest effect size for integrative approaches was for young learners in the elementary level.

\section{Integration of Technology and Students' Performance}

Research on mobile-learning and the use of personal digital assistants (PDAs) found that mobile devices improved the learning of science for $\mathrm{K}$ to 12 students, enhanced their learning motivation, and served as an engaging tool for situated outdoor learning environments (Chang \& Kim, 2009; Chen et.al, 2015; Gomleksiz, 2012; Hwang et.al, 2011; Kim et.al, 2014; Liu et.al, 2014). Research in Taiwan about the integration of e-Books for sixth-graders showed students' positive attitude toward the integration of technology in science curriculum, which was also positively correlated with learning effectiveness. Investigating gender difference, Gomleksiz (2012) found in a research in Turkey that sixth-grade elementary male students considered the learning of science and technology to be more essential than female students did, and thus performed better. However, Wen et.al (2012) found no significant gender difference in Taiwanese schools. Examining motivation factors and achievement in science based on technology use, a study by Ayoub (2015) showed that the integration of active boards improved first-grade students' performance in the Kingdom of Bahrain. One of the strategies that enhanced students' motivation to learn was triggering communication among students, who needed to acquire a logical flow of reasoning supported by evidence (Hardy et.al, 2010). 


\section{Reasoning, Communication Skills and Science}

In their analytical study on classroom discourse in science classes, researchers maintained that scientific claims needed to be supported with evidence which required students to have logical reasoning skills (Hardy et al., 2010; Wu, Weng, and She, 2016). Thus, "reasoning is the logic for why the evidence supports the claim, which can often include scientific principles", (McNeill, Lizotte, Krajcik \& Marx, 2006, p. 156). According to the OECD and others, reasoning was strongly associated with oral and written communication in addition to argumentative discourse (Hardy et.al, 2010; McNeill et.al, 2006). In Lebanon, the National Center for Educational Research and Development (NCERD, 1999) defined scientific communication as composing a text or doing a display of the results. It involved using a suitable language in scientific writing in addition to tracing curves, diagrams and charts, and constructing tables. In light of the latter findings, there had to be a substantial consideration for technology and its use in enhancing the abovementioned skills due to its strong relevance to higher-order-thinking skills which in turn established a baseline and a rationale for the study at hand.

\section{Theoretical Framework}

Many interrelated factors lead to the integration of technology in schools such as the vision and mission, the principals' and teachers' attitudes and practices, technological infrastructure, curriculum review, professional development and other student-related factors (Coleman et al., 2016; Tay et al., 2015). Therefore, science learning using technology could be viewed as a process where there is a need to interrelate critical thinking and students' knowledge. This requires teachers to actively engage students in constructive discussions based on scientific thinking in order to ask questions, give assumptions, and look for evidence to support the shared arguments (Cakir, 2011). In this regard, Bloom's higher order thinking skills require teachers to use instructional strategies that reduce memory-overload and stimulate the working-memory. Researchers refer to prior knowledge to help students relate new information to previous ones and build on them (Bou Jaoude, 2018; Hughes, 2014; Krathwohl, 2002). In his definition of critical thinking, Hughes included the improvement of memory, reasoning, analysis, hypothesis testing, decision-making and problem solving. Moreover, with the expansion of technology, the Internet emerged as an advanced means of communication, information, and cognitive scaffolding, which enhanced higher-order thinking skills such as the application and evaluation of data (Johnson, 2010). According to Vygotsky (1930), to help a child acquire knowledge, adults need to determine the child's problem-solving ability as he/she works alone, and to discover what the same child could do with adult guidance. The difference between the latter two functioning levels was defined as the zone of proximal 
development (ZPD) (Altuna \& Lareki, 2015; Olson, Greenfield, Gardner, and Cole, 2017). Jerome Bruner's (1966) research corroborated with that of Vygotsky's regarding the nurturing role of the environment where culture was considered to be the great molder of thinking and language the key to cognitive development. Altuna and Lareki (2015) described this culture as an active interaction between participants and their environment, having the teacher acting as a mediator for knowledge construction. In our study, the culture would be that of ongoing learning using technology, through the lens of social constructivism.

In a study on the situated learning theory, Hwang et.al, 2011, found out that placing students in realistic learning environments would improve their learning gains; this was also confirmed in research on the same topic (Cakir 2011; Wen et.al, 2012; Magnifico, Olmanson, and Cope, 2013; Chen et.al., 2015). However, other studies revealed negative results regarding students' motivation in using technology. Demotivating factors included secondlanguage learners' understanding of technical and scientific terms, and the cost of technology means as highlighted by students (Chang \& Kim, 2009; Efe, 2015).

\section{Context of the Study}

This research was done in Lebanese schools. Lebanon is a MiddleEastern country that has been long known for its combined instructional institutions ranging from public, semi-private, and private schools (Dandashly, 2014). Arabic is the mother-tongue language of all educational institutions while French and English are the second languages of instruction. Three private elementary schools participated in this study. The language of instruction was Arabic and English in each of the three schools, namely English for science. Furthermore, in addition to the Lebanese curriculum developed in 1997, the three schools were implementing a foreign curriculum: two of them were using an American curriculum and the third used a British one. The schools had a technology-enhanced learning environment which provided students with active boards in each class; the student-computer ratio was 2:1 in computer laboratories.

Science was taught in elementary schools as an interdisciplinary subject comprising physics, chemistry, earth science and life science in addition to acquiring technology and English-language skills. Integration of technology in their curricula was combined with inquiry-approaches to instruction and required the use of hands-on experiments as stated in the schools' policies. 


\section{Methods}

This study followed the exploratory sequential mixed methods design based on case studies to observe the integration of technology in teaching science, and understand participants' perceptions of learning gains in science.

\section{Population and Sample}

Three private schools were purposively selected from Beirut and the Metn region, two K-12 schools and one K-6. The sample consisted of three Heads of Elementary Schools who were all female, 164 grade-six boys and girls-students, and four female teachers of whom three were the science coordinators for grade-six sections. The schools were chosen based on their high-technology-use of a computer laboratory, laptops and LCDs with a projecting screen and Internet connection, and interactive white boards. The three schools were characterized by teaching science using the English language. School A used an American curriculum. It consisted of three gradesix sections with a total number of 64 students. School B had a British curriculum. It consisted of three-grade six sections with a total number of 75 students, each section comprising 25 students. School C used an American curriculum and was highly involved in integrating educational technologies. It included one grade-six section with 25 students.

\section{Instruments}

Three instruments were developed: an observation tool with openended remarks based on Moukarzel (2011), semi-directed interviews with principals, and a questionnaire to the students (Wu et.al, 2016; Tarng et.al, 2012; Lawson, 2000; NCERD, 1999). Authorization was granted where needed. The semi-structured interviews with the Heads of private elementary schools, teachers, and coordinators had six questions targeting three themes: the school mission and vision, the instructional strategies associated with the integration of technology, and perceptions about students' learning with technology. Each interview lasted around fifteen minutes. The observation tool covered five main aspects including the use of teaching strategies with technology, the level of questions the teachers asked, the type of interaction in class between teachers and students, the type of written requirements in class, and general remarks about the premises and classroom management. With the questionnaire to students, we collected demographic data and inquired about their perceptions of science learning with technology. The questionnaire consisted of 12 items using a Five-Point-Likert scale ranging from strongly agree as the highest point to strongly disagree as the lowest point with undecided as a mid-level (Wu et.al, 2016; Tarng et.al, 2012). These instruments helped in triangulating results for more accuracy. 


\section{Data Analysis}

Interviews were audio-taped and transcribed; then, the data was coded and four categories were generated: 1) the school mission and vision, 2) the used technological tools, 3) the most beneficial tools for teaching science, and 4) instructional strategies associated with technology integration in science classes. To analyze class observations, we completed an observation grid during each of the seven sessions, and hand notes were written in the openended space under the section of "comments". Data from this instrument was coded, categorized and analyzed, and then findings were compared to the ones from interviews. As for the responses collected from the questionnaires, we used the Statistical Package for the Social Sciences (SPSS) software to calculate the means and frequencies for each school and represented them in the tables 1 and 2 .

\section{Findings}

Findings from Interviews with Administrators, teachers and coordinators

The three Heads of schools had a positive attitude toward the use of technology at the elementary level. In school A, the Head, coordinator, and teacher confirmed the beneficial outcome of using technology on students' learning. When asked about their role in guiding students toward the school's mission and vision, the Head referred to integrating $21^{\text {st }}$ century skills, pointing out the benefits of technology use in the following terms: "(...) I say to a certain satisfactory level because technology really gives the dimension of reality so students can practice science in real-life in a meaningful way, and it helps in diminishing obscure topics helping them visualize everything and see the things...". As when asked about their instructional practices in using technology, all of them said that they used the active board, I-pads, cellphones, $\mathrm{Wi}-\mathrm{Fi}$, and the VR tools for virtual experiments. The difference between the teacher and coordinator was only related to which one was considered the most beneficial tool for the technology-enhanced learning integration: the active board or the I-pad. The science coordinator stressed out that simulations were important to students who would not "(...) learn only theories; they need to discover for example when they learn about systems how can they observe the parts of the digestive systems and see the journey of the food in the digestive system". She elaborated a lot on the use of simulations saying that these were "something basic (...); some experiments are difficult to perform in reality; we may use simulations to get the concept. We also use virtual labs as simulations ...sometimes we have toxic substances we cannot add during chemistry sessions for chemical reactions so they can observe the signs of chemical reactions using simulations. We use the active board for simulations and after that students apply in the lab using the materials they have." Back and forth with the use of technology, the science teacher added the dimension of active 
learning strategies using prompts to generate students' solutions in addition to integrating them in group work.

On the other hand, in school B, answers given by the Head and the science coordinator during interviews were not always congruent. Although they both stated that students' science learning with technology was "excellent" and "high", they both did not mention anything related to the use of technology when asked about the school's mission and vision. Nevertheless, when asked about instructional strategies and technological means, the Head emphasized the usage of the active board, flipped learning, developing critical thinking, independent learning strategies, and formulating questions. While she also stated that technology and video games decreased students' concentration, the science coordinator confirmed that the use of videos and the active board were efficient tools but she did not mention any of the strategies and practices implemented, adding that they only made use of videos and not of any type of "games", associating thus simulations to gaming. The coordinator also reflected that she preferred to have hands-on experiments because "touching things makes you remember what you did".

As for School C, when asked about their role in guiding teachers toward the vision and mission, the Head mentioned that they were developing "global citizens of the world capable of facing future challenges". This was somehow similar to the Head of School A answer but different from that of School B Head.

It was obvious in the interviews, that among the three schools in the study, school $\mathrm{C}$ had the highest frequency and tendency of integrating technology. The Head and the science coordinator's perspectives were congruent as they both separately emphasized the school's role in bringing $21^{\text {st }}$ century learners to become problem solvers and critical thinkers. Moreover, regarding the instructional strategies and means associated with technology, both stressed that they were adapting online resources to the type of lessons offered; they were also supporting teachers in developing their technology skills. As such, the science coordinator confirmed: "(...) we put plenty of interactive flipcharts, we put power points, we are using the augmented reality and the science department is the only department at school that implements online Math and Science quizzes." Furthermore, the opinion of the Head and coordinator regarding students' learning using technology was alike. They both referred to using QR codes and Web 2.0 tools. The Head told us: “(...) the more the tools are interactive, the more they are useful and accomplish your target."

In conclusion, answers emerging from schools $\mathrm{A}$ and $\mathrm{C}$ interviews reflected a high coherence and consistency of purposes and goals among the school Heads, coordinators and teachers. While school B was found to have 
less coherence and common purpose in guiding the teaching and learning process regarding technology integration.

\section{Results from Students' Questionnaires}

One hundred and sixty-four students from grade- six completed the questionnaire about their perceptions of using technology and its effects on their reasoning and communication skills. In school A, 64 students filled the questionnaire while in school B, 75 answered and in school C, 25 did. The questionnaire comprised 9 items for reasoning and 3 items for communication. A five-point Likert scale was used ranging from "strongly agree" to "strongly disagree" with a mid-point for "undecided". Descriptive statistics were calculated; the percentages for "agree" and "strongly agree" were merged and considered under affirmative answers.

\section{Students' Responses for Reasoning Skills (Table 1).}

In school A, students' perceptions ranged from a minimum of $68.6 \%$ on the item "critiquing the results obtained" to a maximum of $88 \%$ for "analysis" which is above the item "pick up information" $(83 \%)$, with a total average of $76 \%$ on reasoning. In school B, the percentages ranged from $56.5 \%$ for the item "critique the results obtained" to $89 \%$ for the item "pick up information" with a total average of $75 \%$ on reasoning. As for school $\mathrm{C}$, the lowest percentage was $62.6 \%$ on "critique the results obtained" and the highest was $92 \%$ on the item "pick up information"; the average for school C was $80 \%$. Consequently, students' perceptions of their reasoning skills were relatively higher in schools A and $\mathrm{C}$ than in B. Furthermore, students in the three schools had a considerably high score on the lower reasoning skill of "pick[ing] up information" and "completing a KWLH" table. Consequently, students in the three schools had high perceptions of learning gains from technology use on the lower reasoning skills. However, for the item "compare/ contrast", there were somehow varied percentages: in school A, 70\% had positive perceptions, while in school B, 63\% seemed to know about it; the highest was in school C with $84 \%$ of students considering that they knew how to compare and contrast variables in science. Interestingly, the item "Ask about the causes of appearance of an observed result" which is at a higher level in Bloom's taxonomy than the preceding one was perceived more positively with $70 \%$ in school A, and 82\% in schools B and C. Some variation appeared in School C with students perceiving that they were less performant in "suggest[ing] a prediction" with $60 \%$, while in schools A and B, the results showed respectively $75 \%$ and $71 \%$, more consistent with the previous two items related to comparing and asking about causes. Students' perceptions regarding "analysis" were high in the three schools with $88 \%, 83 \%$ and $89 \%$ in schools $\mathrm{A}, \mathrm{B}$, and $\mathrm{C}$ respectively. As for the two levels related to conclude and evaluate, 
students' perceptions about their learning gains were somehow alike with $75 \%$ and $72 \%$ for school $\mathrm{A}$ and $73 \%$ for both in school B. In school C, students had, as for other items, a high perception of their gains using technology (81\% for "Derive conclusions from the experiment" and $86 \%$ for "Evaluate the correctness of the used tests"). On the last item, for the three schools, students had low perceptions $(68.6 \%$ in school A; $56.5 \%$ in school B; $62.6 \%$ in school C). Hence, students were aware of their limitations regarding this level in reasoning.

Table 1. Percentages of students' affirmative answers on the reasoning items

\begin{tabular}{|c|c|c|c|}
\hline Reasoning Items & $\begin{array}{l}\text { School A } \\
\text { Percentage }\end{array}$ & $\begin{array}{l}\text { School B } \\
\text { Percentage }\end{array}$ & $\begin{array}{l}\text { School C } \\
\text { Percentage }\end{array}$ \\
\hline 1- $\quad$ Pick up information & $83 \%$ & $89 \%$ & $92 \%$ \\
\hline Complete a KWLH table & $83 \%$ & $83 \%$ & $84 \%$ \\
\hline Compare/contrast variables & $70 \%$ & $63 \%$ & $84 \%$ \\
\hline $\begin{array}{l}\text { 4- Ask about the causes of } \\
\text { appearance of an observed result }\end{array}$ & $70 \%$ & $82 \%$ & $82 \%$ \\
\hline 5- $\quad$ Suggest a prediction & $75 \%$ & $71 \%$ & $60 \%$ \\
\hline Analyze the result & $88 \%$ & $83 \%$ & $89 \%$ \\
\hline $\begin{array}{l}\text { 7- Derive conclusions from the } \\
\text { experiment }\end{array}$ & $75 \%$ & $73 \%$ & $81 \%$ \\
\hline $\begin{array}{l}\text { 8- Evaluate the correctness of the } \\
\text { used tests }\end{array}$ & $72 \%$ & $73 \%$ & $86 \%$ \\
\hline 9- Critique the results obtained & $68.60 \%$ & $56.50 \%$ & $62.60 \%$ \\
\hline Average & $76 \%$ & $75 \%$ & $80 \%$ \\
\hline
\end{tabular}

Students' Responses for Communication Skills (Table 2).

The oral and written communication skills were measured through three items. The average of responses varied from one school to another with the lowest being in school B (63.57\%), 67.27\% in school A, and 82\% in school C.

Regarding the written communication, responses in school $\mathrm{C}$ had the highest percentage of $86 \%$, followed by school B with a $68.4 \%$, while school A had the lowest percentage of $63.6 \%$. For the oral communication skills, responses to two items were requested: for the item "Explaining the concept orally using clear and appropriate scientific terms", students perceived themselves highly with $82 \%$ in school C, while students in schools B and A were far below with respectively $68.1 \%$ and $65.5 \%$. For the second item "Explaining my scientific thoughts orally, fluently, and using coherent and consistent word flow", school C students had again the highest perceptions of themselves with a percentage equal to $78 \%$, while in school A they had slightly lower perceptions of $72.7 \%$, but the least self-perceptions were notably for school B with a percentage of $54.2 \%$. 
Table 2. Percentages of "Strongly Agree" and "Agree" scores on the communication items

\begin{tabular}{|c|c|c|c|}
\hline Communication & School A & School B & School C \\
\hline $\begin{array}{l}\text { 1- Write a meaningful text of } 3 \text { to } 4 \text { sentences } \\
\text { using clear appropriate scientific words }\end{array}$ & $63.60 \%$ & $68.40 \%$ & $86.00 \%$ \\
\hline $\begin{array}{l}\text { 2- Explain the concept orally using clear and } \\
\text { appropriate scientific terms }\end{array}$ & $65.50 \%$ & $68.10 \%$ & $82.00 \%$ \\
\hline $\begin{array}{l}3-\text { Explain my scientific thoughts orally, } \\
\text { fluently, and using coherent and consistent word } \\
\text { flow }\end{array}$ & $72.70 \%$ & $54.20 \%$ & $78.00 \%$ \\
\hline Average & $67.27 \%$ & $63.57 \%$ & $82.00 \%$ \\
\hline
\end{tabular}

\section{Findings from Classroom Observations}

Seven class observations were done in grade-six sections in the three schools: three observations in school A, three in school B, and one in school C. The classroom observation grids were mostly based on Bloom's taxonomy for reasoning, at the levels of knowledge, comprehension, application, analysis, synthesis, and evaluation. For communication, our observations focused more on the oral than the written skills. Notes were taken during the whole period spent in class regarding teaching strategies, students' participation, and activities meant to enhance learning.

In school A, the three grade-six science sections were observed. The science coordinator taught two sections while another teacher taught the third one. The science coordinator integrated technology in association with criticalthinking questions and used active learning strategies such as posing problems and eliciting students' responses through worksheets and charts. The students in her classes worked in groups, shared information, and solved their worksheets collaboratively. This was reflected by the students' more frequent demonstration of reasoning skills namely at the levels of "picking up information", "identifying variables", "differentiating cause/effect relations", and "analyzing data". In the third section, the teacher used the active board to show processes such as digestion and blood circulation and then asked students to explain what they understood in their own words or to summarize information without the use of direct applications for higher order thinking skills. More questions from Bloom's lower cognitive levels were asked such as summarizing questions, repeating information; only one concluding question was requested.

In school B, the science coordinator taught the three sections and her instructional practices were the same in all the classes. She equally integrated the active white board in association with worksheets that triggered students' higher-order thinking skills in addition to questions at the levels of memory and understanding. However, students were working individually and not in pairs or groups at any time. Students in each class responded differently depending on the timing of the science period; for instance, the last two periods were marked by lower levels of interaction and participation among students 
than the first three periods of the day. Moreover, the classes themselves had different levels of interaction with the same teacher due to varied English language proficiency in addition to versatile cognitive levels of responses; some students could not support their answers with evidences from the board while others elaborated on these and went beyond the basic given information, replying accurately to questions such as "what evidence do you have to support your claim?", "what can you conclude?" and "how would you analyze such results?"

As for School $\mathrm{C}$, it had only one grade-six section with the science coordinator as teacher. The observed coordinator used technological/simulation tools such as augmented reality applications and VR tools, in addition to the interactive white board. However, the coordinator did not integrate questions at the levels of analysis or beyond nor did she use worksheets or charts during her explanations. She did not integrate active learning strategies such as group work or think/pair/share. Her main focus revolved around understanding the simulation, picking up information, and memorizing the observed process or phenomenon. These were reflected in fewer occurrences of "deriving conclusions", "analysis", and "interpretation" for students in school C.

Regarding the observed communication skills, School A, had the highest level of "group communication skills", "using clear and understandable English". However, it had lower instances of "explaining concepts orally using clear scientific terms" and "explaining thoughts frequently and coherently": 10 students per session and per class. While, classes in school B had a higher number of students performing the latter two skills: 14 students per session and per class. On the other hand, though, we observed a high level of technology use in School C class, surprisingly, students showed the lowest levels of oral communication skills since they had only 7 students participating in class. They could not use the appropriate scientific terms to explain their thoughts and present their ideas. As for the written communication skills, in school A, almost all students were on task during the group work and were involved in writing responses to given questions, except for one or two per activity. In school B, since they were handed individual worksheets, almost all students were writing their responses and we could listen to their written solutions, which means that the items "writing a meaningful text" and "drawing a table or graph" were attended to. However, the written communication skills could not be observed in school C, because the teacher did not require the students to write any task. As for the item related to "analysis of a table or graph", it was not observed in the three schools because none of the teachers asked the students to do these applications in the classroom setting. 


\section{Discussion}

Benefits of Technology Use in Learning Science for Grade-six Students

Findings from the interviews with the science coordinators, teachers and Heads of the three schools showed that the interviewees considered technology to be beneficial but to varied extents. Thus corresponding to what many recent studies emphasized about the importance of the integration of technology in improving students' thinking skills and achievement in addition to increasing students' motivation to learn science (Becker \&Park, 2011; Cakir, 2011; Mashizi \& Rezaian, 2014; Hardy et al., 2010; Chang \& Kim, 2009). In school A, an obvious coherence among the Head of elementary school, coordinator, and grade-six-teacher about the beneficial effects of using technology was noticed. The latter was confirmed through the triangulated findings from the observations, interviews and questionnaires. The shared vision of a culture of technology literacy associated with critical thinking skills was documented by the observation grids used in this study and was reflected in students' questionnaires who had high perceptions in this respect. The latter finding corroborated with a study by Tay et.al, in 2015 which mentioned that teachers' beliefs and practices were crucial for the successful integration of Information Communication Technology in addition to the school policy and leadership, technological infrastructure, and curriculum and assessment (Sparapani \& Calahan, 2014; Tay et.al, 2015). On the other hand, School C had the highest consistency in opinion regarding the integration of $21^{\text {st }}$ century skills and critical thinking using technological aides. Students' perceptions in the questionnaire confirmed the interview findings and reflected the positive effect of having a consistent vision and mission among the school leader and its faculty on students' beliefs, however, the class observations negated the upper levels of critical thinking since teachers did not bring their students to analyze scientific problems, evaluate or critique results obtained nor did students ask questions at these levels. As for school B, a discrepancy was evident between the science coordinator's thinking regarding technology integration and the higher emphasis on this regard expressed by the Head of the elementary school. This inconsistency was reflected through the students' responses in the questionnaire with the lowest perceptions of learning gains from technology use among the three schools. Therefore, and as Tay et al. (2015) stated, teachers' practices with respect to technology integration were projected on the students, which did not alter students' high levels of reasoning and communication skills found during class observations. Consequently, we could say that School B students had a more realistic view of their skills and abilities and did not perceive themselves highly in technology use due to the teacher's lower emphasis on this issue. 


\section{Science Reasoning Skills and Technology for Grade-Six Students}

Grade-six students in the three schools had high perceptions of learning gains from technology integration with respect to improving their reasoning skills though more in schools $\mathrm{A}$ and $\mathrm{C}$ than in School B. However, the perceptions were higher at the lower levels of Bloom's Taxonomy such as to "pick up information", "compare/contrast" and "ask questions". Nevertheless, at the "analysis" level, students in the three schools had notably high perceptions of their performance. Yet, their perceptions of learning gains were remarkably lower for high reasoning levels and especially for "critiquing the results obtained". These corroborated with what was reported in the observation grids, though the "analysis" part could not be observed and thus remained under question. In that regard, interviews with teachers reflected more their use of technology than their daily practices to raise students' higherorder reasoning skills, although the interviewed Heads expressed their willingness to target them. Nevertheless, in school A, both the teacher and coordinator's interviews and observations revealed that they were using critical thinking questions, worksheets, and prompts in association with the technological means. School B observations and interviews also showed that they integrated higher-order thinking skills although the use of technology was less frequent than in schools $\mathrm{A}$ and $\mathrm{C}$. Thus, our findings indicated that technology is only a means to raise higher order reasoning skills if associated with appropriate teaching practices. It was clear that students in school C were very much motivated with their teacher's intensive use of technology, but their performance did not seem to match their perceptions regarding reasoning which was not the case for schools A and B. This was found to be in line with many recent research findings (Becker \&Park, 2011; Cakir, 2011; Mashizi \& Rezaian, 2014).

\section{Technology and Students' Communication skills}

Findings from class observations were important for a primary exploration of oral and written communication in grade six. Communication in school A was found to be enhanced by combining active learning strategies, mainly group work, with the used interactive white board. The latter was confirmed by students' oral presentations of their written work and their active interaction during group work. Concurrently, students' responses in the questionnaire also affirmed their high perceptions of being able to communicate orally and in writing with the help of the integrated technology, which was also confirmed by the interviewed Head, coordinator, and teacher. The afore-mentioned corresponded to research findings on the use of technological tools to support students in learning science with increased motivation (Chen et.al, 2015; Kim et.al, 2014; Liu et.al, 2014). As for school $\mathrm{B}$, students were held personally accountable for responding to written tasks, 
since they were not involved in group work. While they had to respond separately to the teacher's oral questions, findings from observation grids showed that they had good oral and written communication skills which was also confirmed by the interviews with the school Head and the science coordinator. Interestingly, the analysis of school $\mathrm{C}$ results showed that students had the highest frequency of technology usage and the highest perceptions of learning gains regarding communication items. However, it was observed that they were poor on oral and written communication skills despite the high motivation and participation levels they showed as triggered by technology use. According to research, one of the strategies that enhanced students' motivation to learn was to create for them opportunities for communication to help them develop a logical and sequential thinking supported by evidence (Hardy et.al, 2010). Consequently, the extensive use of technology without engaging students in active learning and group work diminished their communication skills.

\section{Conclusion}

In conclusion, requirements for active learning and critical thinking skills associated with the use of technology made the teaching and learning process even more complex in science. While it was noticeable that students were becoming more digital natives, teachers were more digital immigrants as defined by Chaves, Maia and Melo (2016). We saw in our study that the excessive use of technology hindered communication and disoriented students' learning, while the lack of technology reduced their technical skills. Therefore, a deep understanding of students' needs and their teachers' in-service development would be necessary. This could lead to rethinking the possibility of collaborative efforts among school leadership and policy makers, curriculum developers, teachers, parents and stakeholders to develop new ways to improve the science learning process.

\section{Implications and Recommendations}

Future research about the effective use of technology to enhance students' higher-order thinking skills needs to be done combined with appropriate teaching strategies. These would open doors for teachers' professional development at all three levels: technology, teaching strategies to enhance higher order thinking skills, and student motivation for better achievement.

\section{References:}

1. Al-Naqbi, A.K. (2015). The Fundamental Abilities of Inquiry in The Elementary Science Workbooks: The Case of UAE Northern Schools. International Interdisciplinary Journal of Education. 4(4), 1-12. 
2. Altuna, J. and Lareki, A. (2015). Analysis of the Use of Digital Technologies in Schools that Implement Different Learning Theories. Journal of Educational Computing Research. 53(2), 205-227.

3. Ayoub, J.M.A (2015). The Effect of Complementarity between the Learning Cycle and E-Learning on Achievement in Science for FirstGrade Students in Bahrain. USJ: Beirut.

4. Becker, K., and Park, K. (2011). Effects of Integrative Approaches among Science, Technology, Engineering, and Mathematics (STEM) Subjects on Students' Learning: A Preliminary Meta-Analysis. Journal of STEM Education. 12(5, 6), 23-37.

5. Bou Jaoude, S. (2018). Instructional strategies to promote critical thinking: The Eighth International Conference on Effective Teaching and Learning in Higher Education. AUB: Beirut.

6. Cakir, M. (2011). Enhancing Mendelian Genetics Concepts Using a Guided Computer- Mediated Inquiry. Journal of Baltic Science Education. 10(3), 156-167.

7. Creswell, J.W. (2014). Research Design. Croydon: Sage.

8. Chang, M., and Kim, S. (2009). Computer Access and Computer Use for Science Performance of Racial and Linguistic Minority Students. Educational Computing Research, 40(4),469- 501.

9. Chaves, H., Maia, O.N., and Melo, A.S. (2016). Education in Times Net Generation: How Digital Immigrants Can Teach Digital Natives? Holos. 32(2), 347- 356.

10. Chen, C.H., Wang, K.C., and Lin, Y.H. (2015). The Comparison of Solitary and Collaborative Modes of Game-based Learning and Motivation. Educational Technology and Society. 18(2), 237-248.

11. Coleman, L., Gibson, P., Cotton, S.R., Howell-Moroney, M., and Stringer, K. (2016). Integrating Computing Across the Curriculum: The Impact of Internal Barriers and Training Intensity on Computer Integration in the Elementary School Classroom. Journal of Educational Computing Research. 54 (2), 275-294.

12. Dandashly, N.A. (2014). The Effects of the Language of Instruction in theScience and Math Achievement of Lebanese Students. LAU: Beirut.

13. Efe, H.A. (2015). The Relation between Science Student Teachers' Educational Use of Web 2.0 Technologies and Their Computer SelfEfficacy. Journal of Baltic Science Education. 14(1). 142-154.

14. Gomleksiz, M.N. (2012). Elementary School Students' Perceptions of the New Science and Technology Curriculum by Gender. Educational Technology and Society. 15(1), 116-126.

15. OECD. (2013). PISA 2015 Draft Science Framework. Paris: OECD.

16. Hardy, I., Kloetzer, B., Moeller, K., and Sodian, B. (2010). The Analysis of Classroom Discourse: Elementary School Science 
Curricula Advancing Reasoning with Evidence. Educational Assessment, 15, 197-221.

17. Hughes, C. (2014). Theory of Knowledge Aims, Objectives, and Assessment Criteria: An Analysis of Critical Thinking Descriptors. Journal of Research in International Education. 13(1), 30- 45.

18. Hwang, G.J., Shi, Y.R., and Chu, H.C. (2011). A Concept Map Approach to Developing Collaborative Mind Tools for Context-Aware Ubiquitous Learning. British Journal of Educational Technology. 42(5), 778-789.

19. Johnson, G.M. (2010). Internet Use and Child Development: Validation of the Ecological Techno-Subsystem. Educational Technology and Society. 13(1), 176-185.

20. Kim, K.H., Basca, J.V., Bracken, B.A, Feng, A., and Stambaugh, T. (2014). Assessing Science Reasoning and Conceptual Understanding in the Primary Grades Using Standardized and Performance-Based Assessments. Journal of Advanced Academics, 25(1), 47-66.

21. Krathwohl, D.R. (2002). A Revision of Bloom's Taxonomy: An Overview. Theory into Practice, 41(4), 212-222.

22. Lawson, A.E. (2000). Classroom Test of Scientific Reasoning: Multiple Choice Version. Journal of Research in Science Teaching, 15(1), 11-24.

23. Liu, M., Scordino, R., Geurtz, R., Navarrete, Y. K., and Lim, M. (2014). A Look at Research on Mobile Learning in K-12 Education from 2007 to the Present. Journal of Research on Technology in Education, 46(4), 325-372.

24. Magnifico, A.M., Olmanson, J., and Cope, B. (2013). New Pedagogies of Motivation: Reconstructing and Repositioning Motivational Constructs in the Design of Learning Technologies. E-Learning and Digital Media. 10(4), 483-511.

25. Mashizi, M.K., and Rezaian, F. (2014). Effects of Computer-Assisted Instruction on Sciences by Second Grade Elementary Students. Advances in Environmental Biology. 8(7), 2566-2568.

26. McNeil, K.L., Lizotte, D.J., and Krajcik, J. (2006). Supporting Students' Construction of Scientific Explanations by Fading Scaffolds in Instructional Material. The Journal of the Learning Sciences. 15(2), 153-191.

27. Moukarzel, D. (2011). The Professional Development of Independent School Teachers in Qatar:A Case Study. University of Haute Alsace: Mulhouse.

28. National Center for Educational Research and Development. (1999). Evaluation Guide de L'Enseignant Sciences Generales (Evaluation Guide of Students in General Sciences). Lebanon: NCERD. 
29. OECD. (2009). PISA 2009 Assessment Framework, Key Competencies in Reading, Mathematics, And Science. Paris: OECD.

30. OECD. (2013). PISA 2015 Draft Science Framework. Paris: OECD.

31. Olson, D.R., Greenfield, P.M., Gardner, H.E., and Cole, M. (2017). In Memoriam: Jerome Bruner (1915-2016). Polymath and Pioneer in Cognitive Development and Education. Journal for The Study of Education and Development. 40(4), 744-753.

32. Rappolt- Schlichtmann, G., Daley, S.G., Lim,S., Lapinski, S.,Robinson, K.H., and Johnson, M. (2013). Universal Design for Learning and Elementary School Science: Exploring The Efficacy, Use, and Perceptions of a Web-Based Science Notebook. Journal of Educational Psychology. 105(4), 1210-1225.

33. Sparapani, E.F., and Calahan, P.S. (2015). Technology in Mathematics and Science: An Examination and Comparison of Instructional Use in the United States and Taiwan. Education, 136(2), 242-252.

34. Tarng, W., Chang, M., Ou, K., Yu, K., and Hsieh, K. (2012). The Development of a Virtual Farm For Applications in Elementary Science Education. International Journal of Distance Education Technologies, 10(2), 1-16.

35. Tay, L.Y., Lim, C.P., and Lim, S.K. (2015). Differences in ICT Usage Across Subject Areas: A Case of an Elementary School in Singapore. Journal of Educational Computing Research, 53(1), 75-94.

36. Ucak, E., and Bag, H. (2012). Elementary School Pupil's Self Efficacy Towards Science and Technology Lesson. Journal of Baltic Science Education. 11(3), 203-215.

37. Wen, J.R., Chuang, M.K., and Kuo, S.H. (2012). The Learning Effectiveness of Integrating E-Books into Elementary School Science and Technology Classes. International Journal of Humanities and Arts Computing. 6(1), 224-235.

38. Wu, H.L., Weng, H.L, and She, H.C. (2016). Effects of Scaffolds and Scientific Reasoning Ability on Web-Based Scientific Inquiry. International Journal of Contemporary Educational Research. 